\title{
The Tyrosine Phosphatase STEP Mediates AMPA Receptor Endocytosis after Metabotropic Glutamate Receptor Stimulation
}

\author{
Yang Zhang, ${ }^{1}$ Deepa V. Venkitaramani, ${ }^{1}$ Clare M. Gladding, ${ }^{2}$ Yongfang Zhang, ${ }^{1}$ Pradeep Kurup, ${ }^{1}$ Elek Molnar, ${ }^{2}$ \\ Graham L. Collingridge, ${ }^{2}$ and Paul J. Lombroso ${ }^{1}$ \\ ${ }^{1}$ Child Study Center, Yale University School of Medicine, New Haven, Connecticut 06520, and ${ }^{2}$ Medical Research Council Centre for Synaptic Plasticity, \\ Department of Anatomy, School of Medical Sciences, University of Bristol, Bristol BS8 1TD, United Kingdom
}

\begin{abstract}
Although it is well established that AMPA receptor (AMPAR) trafficking is a central event in several forms of synaptic plasticity, the mechanisms that regulate the surface expression of AMPARs are poorly understood. Previous work has shown that striatal-enriched protein tyrosine phosphatase (STEP) mediates NMDAR endocytosis. This protein tyrosine phosphatase is enriched in the synapses of the striatum, hippocampus, cerebral cortex, and other brain regions. In the present investigation, we have explored whether STEP also regulates AMPAR internalization. We found that (RS)-3,5-dihydroxyphenylglycine (DHPG) stimulation triggered a dose-dependent increase in STEP translation in hippocampal slices and synaptoneurosomes, a process that requires stimulation of mGluR5 (metabotropic glutamate receptor 5) and activation of mitogen-activated protein kinases and phosphoinositide-3 kinase pathways. DHPGinduced AMPAR internalization and tyrosine dephosphorylation of GluR2 (glutamate receptor 2) was blocked by a substrate-trapping TATSTEP [C/S] protein in hippocampal slices and cultures. Moreover, DHPG-triggered AMPAR internalization was abolished in STEP knock-out mice and restored after replacement of wild-type STEP. These results suggest a role for STEP in the regulation of AMPAR trafficking.
\end{abstract}

Key words: protein tyrosine phosphatase; STEP; AMPA receptor trafficking; metabotropic glutamate receptor; protein synthesis; ERK1/2

\section{Introduction}

It is well established that AMPA receptor (AMPAR) trafficking is a central event in several forms of synaptic plasticity. For example, AMPARs are inserted into the plasma membrane in NMDA receptor (NMDAR)-dependent long-term potentiation (LTP), whereas AMPARs are internalized in NMDAR-dependent longterm depression (LTD) (Collingridge et al., 2004). A second major form of LTD involves metabotropic glutamate receptor (mGluR) activation and can be readily induced by the selective group I mGluR agonist (RS)-3,5-dihydroxyphenylglycine (DHPG) (Palmer et al., 1997; Huber et al., 2001). This robust chemically induced synaptic plasticity also involves AMPAR internalization (Snyder et al., 2001; Huang et al., 2004).

Little is known about the signaling mechanisms that mediate AMPAR internalization after mGluR stimulation. Previous work, using nonspecific protein tyrosine phosphatase (PTP) inhibitors such as orthovanadate, has pointed to tyrosine dephosphorylation (Huang and Hsu, 2006; Moult et al., 2006), but the identity

Received June 9, 2008; revised July 31, 2008; accepted Sept. 2, 2008.

This work was funded by The National Association of Research on Schizophrenia and Depression, National Institutes of Health Grants MH01527, MH52711, and DA017360 (P.J.L.), a Brown-Coxe fellowship (D.V.V.), and the Medical Research Council (MRC) (G.L.C., E.M.). C.M.G. was an MRC-funded PhD student. We thank laboratory members and Drs. Steven Braithwaite and MariLee Ogren for helpful discussions and critical reading of this manuscript.

Correspondence should be addressed to Dr. Paul J. Lombroso, Child Study Center, SHM I-270, Yale University School of Medicine, 230 South Frontage Road, New Haven, CT 06520. E-mail: paul.lombroso@yale.edu.

DOI:10.1523/JNEUROSCI.2666-08.2008

Copyright $\odot 2008$ Society for Neuroscience ～0270-6474/08/2810561-06\$15.00/0 of the PTP is unknown. Here we test the hypothesis that striatalenriched protein tyrosine phosphatase (STEP) is involved in DHPG-induced AMPAR internalization. STEP is a brain-specific tyrosine phosphatase that regulates LTP, in part, through its ability to modulate NMDAR trafficking (Snyder et al., 2005; Braithwaite et al., 2006b). STEP is found in postsynaptic terminals (Oyama et al., 1995), associates with the NMDAR complex, and constitutively inhibits NMDAR channel functions (Pelkey et al., 2002). Knocking down STEP with interfering RNA increases NMDAR trafficking to synaptic membrane (Braithwaite et al., 2006a). STEP facilitates glutamate receptor endocytosis by dephosphorylation of NR2B at a regulatory tyrosine (Tyr ${ }^{1472}$ ) (Snyder et al., 2005).

This study focuses on whether STEP also regulates AMPAR trafficking. We tested this hypothesis using molecular, biochemical, and imaging methods in both hippocampal slices and primary neuronal cultures.

\section{Materials and Methods}

Materials. DHPG, $(S)-(+)$ - $\alpha$-amino-4-carboxy-2-methylbenzeneacetic acid (LY367385), and 2-methyl-6-(phenylethynyl)-pyridine (MPEP) were from Tocris Bioscience. Anisomycin, cycloheximide, and actinomycin D were from Sigma-Aldrich. $\alpha$-[Amino[(4-aminophenyl)thio]methylene]-2(trifluoromethyl)benzeneacetonitrile (SL327), rapamycin, and 2-(4-morpholinyl)-8-phenyl-4 H-1-benzopyran-4-one (LY294002) were from EMD Biosciences. Primary antibodies (1:1000 dilutions except as indicated below) include phospho-extracellular signal-regulated kinase 1/2 (pERK1/2), pAkt $\left(\mathrm{Ser}^{473}\right)$, Akt, phospho-mammalian target of rapamycin (pmTOR) $\left(\operatorname{Ser}^{2448}\right)$, mTOR, phospho-phosphoinositide-dependent protein kinase 
(pPDK), PDK, phospho-4E-binding protein 1 (p4EBP), 4EBP, GluR1, GluR2 (1:2000), GABA $_{A} \beta 2 / 3$ (Millipore), ERK2 (1:10,000; Santa Cruz Biotechnology), and STEP (23E5) (Boulanger et al., 1995). Horseradish peroxidaselinked donkey anti-rabbit and sheep anti-mouse secondary antibodies were from GE Healthcare.

Tissue preparation and treatments. All procedures were approved by the Institutional Animal Care and Use Committee (Yale University) and United Kingdom Home Office (University of Bristol). Hippocampal slices $(300 \mu \mathrm{m})$ were prepared from either Sprague Dawley rats (male, 170-180 g; Charles River Laboratories) or STEP wild-type (WT) and knock-out (KO) mice (Venkitaramani et al., 2008) (6 weeks) as described previously (Hu et al., 2007). Antagonists were applied 10-20 min before DHPG treatment and present throughout. Subcellular fractionation was performed as described previously (Dunah and Standaert, 2001). Slices were homogenized in ice-cold TEVP buffer, $\mathrm{pH}$ 7.4, containing (in $\mathrm{mm}$ ) 10 Tris- $\mathrm{HCl}, 5 \mathrm{NaF}, 1$ $\mathrm{Na}_{3} \mathrm{VO}_{4}, 1$ EDTA, 1 EGTA, 320 sucrose, and protease inhibitors (Roche). Homogenates were centrifuged at $800 \times g$ for $10 \mathrm{~min}$, and supernatants were then centrifuged at $9200 \times g$ for $15 \mathrm{~min}$. The pellets were resuspended in TEVP buffer containing $36 \mathrm{~mm}$ sucrose and centrifuged at $25,000 \times g$ for $20 \mathrm{~min}$ to yield the synaptosomal membrane fractions (LP1).

Immunoblotting and immunocytochemistry. Proteins $(10-20 \mu \mathrm{g})$ were resolved by $8 \%$ SDSPAGE and transferred to polyvinylidene difluoride membranes. Membranes were incubated with primary antibodies overnight at $4^{\circ} \mathrm{C}$ followed by secondary antibody (1:5000 to $1: 10,000 ; 1 \mathrm{~h}$ at room temperature) incubation. Bands were captured using a G:BOX with GeneSnap image program (Syngene) and quantified by using Image 1.33 supplied by NIH.

Hippocampal neuronal cultures were prepared from STEP WT or KO mice [embryonic day 15 (E15)-E16] embryos as described previously (Hu et al., 2007). Cultures were treated with DHPG for 5 min and fixed in $4 \%$ paraformaldehyde with $4 \%$ sucrose. For AMPAR staining, neurons were incubated for $30 \mathrm{~min}$ in conditioned medium after DHPG treatment before fixation. Cells were permeabilized with $0.1 \mathrm{M}$ PBS, pH 7.4, with $0.2 \%$ Triton X-100 for STEP staining, but not for surface labeling of AMPAR using N-terminal antibodies. Cultures were incubated with $10 \%$ normal goat serum and $1 \%$ bovine serum albumin for $1 \mathrm{~h}$ at room temperature, stained with anti-STEP antibody (1:1000), GluR2 (1:2000), or GluR1 $(1: 250)$ overnight at $4^{\circ} \mathrm{C}$, and incubated with goat anti-mouse Alexa Fluor 594 and/or Alexa Flour 488 secondary antibodies (1:600; Invitrogen). Imaging was performed with a Zeiss Axiovert 2000 microscope with an ApoTome (Applied Scientific Instruments) using a $40 \times$ objective lens. The surface labeling of AMPAR was quantified as described by Tai et al. (2007).

Synaptoneurosome preparation. Synaptoneurosomes were obtained as described previously (Scheetz et al., 2000). Hippocampi were homogenized in ice-cold HEPES buffer containing (in mM) $124 \mathrm{NaCl}, 3.2 \mathrm{KCl}$, $1.06 \mathrm{KH}_{2} \mathrm{PO}_{4}, 26 \mathrm{NaHCO}_{3}, 1.3 \mathrm{MgCl}_{2}, 2.5 \mathrm{CaCl}_{2}, 10$ glucose, and 20 HEPES/NaOH, pH 7.4, with protease inhibitors. Homogenates were centrifuged at $2000 \times g$ for $1 \mathrm{~min}$. The supernatant was passed through two 100 $\mu \mathrm{m}$ nylon mesh filters (Sefar America) followed by a $5 \mu \mathrm{m}$ nitrocellulose filter (Millipore), and centrifuged at $1000 \times g$ at $4^{\circ} \mathrm{C}$ for $10 \mathrm{~min}$.

Surface biotinylation. Assay was performed as described previously (Snyder et al., 2005). Eighty percent of the cell lysate was incubated with $50 \mu l$ of NeutrAvidin agarose (Pierce Biotechnology) to test biotinylated proteins. Data were quantified by comparing the ratio of biotinylated to total proteins ( $10 \%$ of the cell lysate).
B

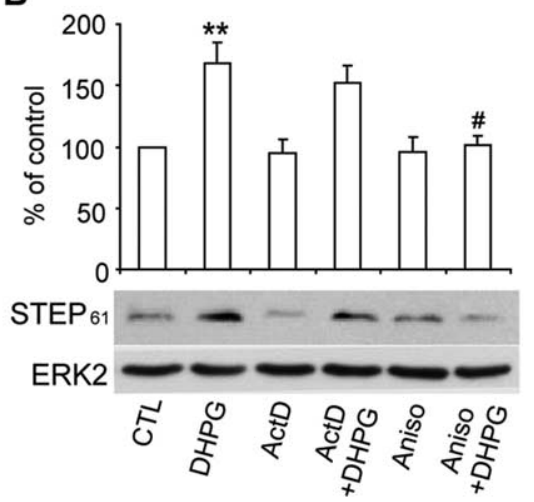

D

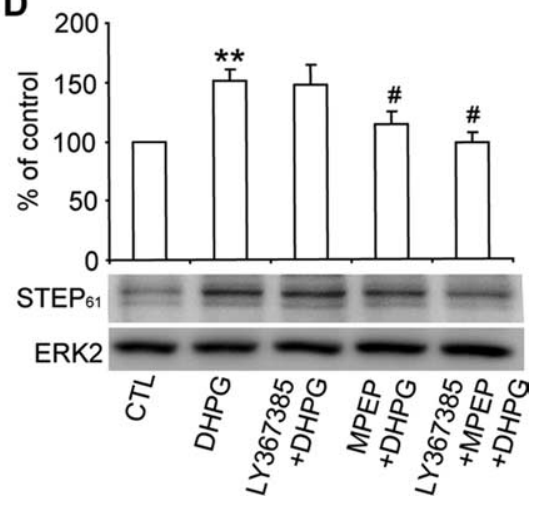

Figure 1. DHPG stimulation increases STEP ${ }_{61}$ levels in hippocampal slices. A, DHPG stimulation at 10, 50, and $100 \mu \mathrm{M} . \boldsymbol{B}$, DHPG theatment in the absence or presence of anisomycin (Aniso) or actinomycin D (ActD). C, DHPG treatment in the absence or presence of SL327 or LY294002. D, DHPG treatment in the absence or presence of LY367385 and MPEP. Total ERK2 was used for normalization [except in C (left), in which tubulin was used]. ${ }^{*} p<0.05,{ }^{* *} p<0.01$ versus CTL; ${ }^{\#} p<0.05$ versus DHPG; $n=4-5$.

Immunoprecipitation. Parasagittal hippocampal slices $(300 \mu \mathrm{m})$ with the $\mathrm{CA} 3$ regions removed were prepared as described previously (Moult et al., 2006). After DHPG treatment, slices were homogenized in a modified radioimmunoprecipitation assay (RIPA) buffer (in $\mathrm{mm}): 1 \%(\mathrm{v} / \mathrm{v})$ Triton X-100, 1\% (w/v) SDS, $0.4 \%$ (w/v) sodium deoxycholate, 2 EDTA, $150 \mathrm{NaCl}, 50$ Tris- $\mathrm{HCl}, \mathrm{pH}$ 7.4, 0.1 genistein, and 1 orthovanadate containing protease inhibitors (Roche) and phosphatase inhibitor mixture 1 (Sigma). Homogenates were heated at $95^{\circ} \mathrm{C}$ for $10 \mathrm{~min}$ followed by a $10 \times$ dilution in RIPA buffer lacking SDS. The samples were centrifuged at $100,000 \times g$ for $1 \mathrm{~h}$, and supernatants were retained. For GluR2 immunoprecipitations, samples were incubated with a mouse anti-GluR2 antibody (Zymed Laboratories; $3.5 \mu \mathrm{g}$ ) overnight at $4^{\circ} \mathrm{C}$, and pulled down with Sepharose G beads (Sigma; $8 \mu$ l per slice).

Statistics. All data are presented as means \pm SE. $n$ indicates number of independent experiments. The significance of difference among multiple groups was evaluated by one-way ANOVA with post hoc Tukey test. A $p<$ 0.05 was considered statistically significant.

\section{Results}

mGluR stimulation increases the translation of STEP in the hippocampus

We first examined whether activation of group I mGluRs regulates STEP protein expression. Hippocampal slices were treated with DHPG (10, 50, and $100 \mu \mathrm{M}$ for $5 \mathrm{~min})$. A dose-dependent increase in $\mathrm{STEP}_{61}$ protein expression is shown in Figure $1 \mathrm{~A}$. $\mathrm{STEP}_{46}$ is not expressed in the hippocampus, and no increase was detected for this isoform (data not shown). We next tested whether the DHPG-induced increase in STEP ( $\mathrm{STEP}_{61}$ isoform) expression was attributable to translational or transcriptional mechanisms. Anisomycin $(40 \mu \mathrm{M})$ or actinomycin D $(25 \mu \mathrm{M})$ was applied 15 min before DHPG $(50 \mu \mathrm{M})$ stimulation. Anisomycin 
A
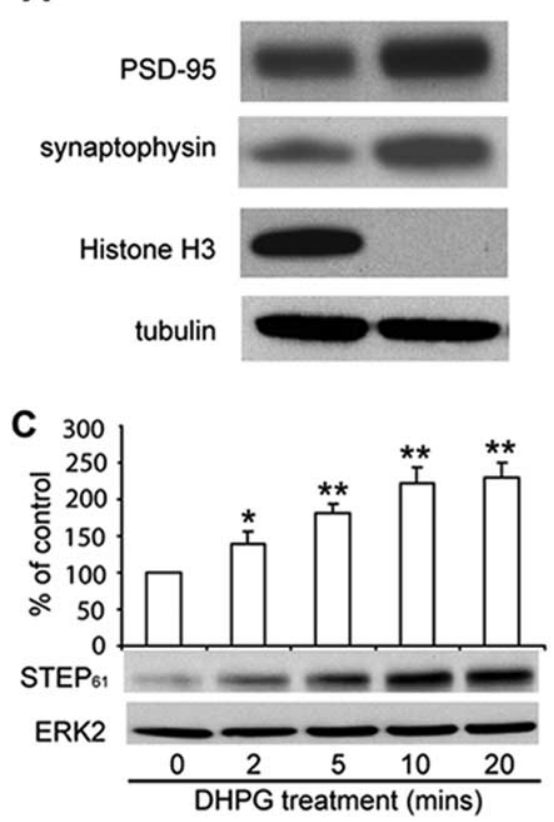
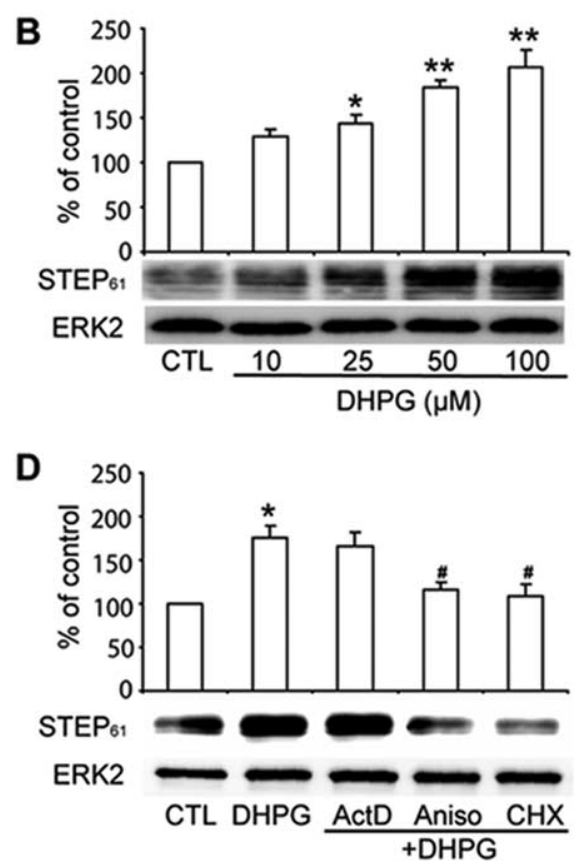

Figure 2. DHPG stimulation increases STEP 61 levels in synaptoneurosomes. $\boldsymbol{A}$, Expected distribution of PSD-95, synaptophysin, and histone in hippocampal synaptoneurosomes (Synap) compared with homogenate (H). $\boldsymbol{B}$, Increased STEP levels after DHPG stimulation. C, Increased STEP levels with DHPG $(50 \mu \mathrm{m})$ over time. D, DHPG treatment in the absence or presence of anisomycin (Aniso), actinomycin D (ActD), and cycloheximide (CHX). ${ }^{*} p<0.05,{ }^{* *} p<0.01$ versus $\mathrm{CTL}^{*}{ }^{\#} p<0.05$ versus DHPG; $n=3$.

blocked the DHPG-induced increase in STEP protein expression without affecting its basal expression, whereas actinomycin D showed no effect (Fig. $1 B$ ). We confirmed these findings by using a second translation inhibitor, cycloheximide $(60 \mathrm{nM})$, which also blocked increased STEP expression [DHPG, $179 \pm 19 \%, p<0.01$ vs control (CTL); DHPG and cycloheximide, $104 \pm 21 \%, p<$ 0.05 vs DHPG; $n=4$ ].

DHPG-induced increase in STEP protein expression requires activation of both ERK and PI3K

Both the mitogen-activated protein kinase (MAPK) and PI3K signaling pathways are required for the translation-dependent form of DHPG-LTD (Gallagher et al., 2004; Hou and Klann, 2004). We therefore explored whether these pathways might underlie the DHPG-induced STEP translation. Preincubation of the MEK (MAPK kinase) inhibitor SL327 $(50 \mu \mathrm{M})$ and the PI3K inhibitor LY294002 $(50 \mu \mathrm{M})$ for $20 \mathrm{~min}$ abolished the DHPGinduced increase in STEP translation without affecting STEP basal expression (Fig. 1C). We also confirmed that DHPG increased the phosphorylation of members of MAPK and PI3K pathways, including ERK, PDK, Akt, mTOR, and 4E-BP1, as described previously (Gallagher et al., 2004; Hou and Klann, 2004; Banko et al., 2006) (data not shown). SL327 and LY294002 blocked the activation of these downstream effectors. We further showed that $20 \mathrm{~min}$ of preincubation with mTOR inhibitor, rapamycin (200 nM), blocked the increase in STEP expression, confirming the necessary involvement of mTOR in DHPG-induced STEP translation (DHPG, $171 \pm 6 \%, p<0.01$; rapamycin + DHPG, $106 \pm 9 \%, p=0.57$; compared with the control; $n=4)$.

\section{DHPG-induced increase in STEP translation requires} activation of mGluR 5

DHPG activates group I mGluRs, mGluR1 and mGluR5, through similar signaling pathways. Although most evidence favors a role for mGluR5 in DHPG-stimulated AMPAR internalization and DHPG-LTD (Huber et al., 2001; Banko et al., 2006; Moult et al., 2006), mGluR1 also plays a role (Volk et al., 2006). To clarify which of these receptors might be involved in the DHPGinduced translation of STEP, we applied specific mGluR5 or mGluR1 inhibitors (MPEP and LY367385, respectively) to hippocampal slices before the addition of DHPG. MPEP $\left(\begin{array}{ll}10 & \mu \mathrm{M}\end{array}\right)$ significantly blocked DHPG-induced increases in STEP translation, but the mGluR1 inhibitor, LY367385 (100 $\mu \mathrm{M})$, had no significant effect (Fig. 1D). STEP translation was completely blocked by mGluR1 and mGluR5 antagonists. The results suggest that the DHPG-induced increase in STEP translation occurs primarily through mGluR5 activation.

\section{DHPG-induced increase in STEP translation occurs} in synaptoneurosomes

Some proteins involved in synaptic plasticity are translated locally in dendrites rather than the cell body, so we tested whether the DHPG-induced translation of STEP occurs, at least in part, within synaptoneurosomes. Synaptoneurosomal preparations were enriched for the synaptic proteins PSD-95 and synaptophysin compared with homogenates, whereas the nuclear marker histone $\mathrm{H} 3$ was not detected (Fig. 2A). Synaptoneurosomes were stimulated by DHPG, and a dosedependent increase in STEP expression was observed (Fig. 2 B). The significant increase was detected as early as $2 \mathrm{~min}$ after $50 \mu \mathrm{M} \mathrm{DHPG}$ (Fig. 2C). STEP synthesis in synaptoneurosomes was blocked by two functionally distinct translational inhibitors, anisomycin and cycloheximide, and was not affected by actinomycin D (Fig. 2D). These results suggest that the DHPG-induced increase in STEP expression occurs in synaptoneurosomes.

\section{DHPG-induced AMPAR endocytosis requires translation of STEP}

Group I mGluRs activation triggers protein translationdependent endocytosis of both GluR1 and GluR2 receptors (Snyder et al., 2001). Moreover, DHPG-induced redistribution of GluR2 requires an unknown PTP (Huang and $\mathrm{Hsu}, 2006$; Moult et al., 2006). We therefore tested the hypothesis that DHPGinduced STEP translation may play a role in the regulation of AMPAR endocytosis. Glutamate receptor trafficking has been studied with subcellular fractionation (Dunah and Standaert, 2001), and we used a similar approach to look at receptor expression in synaptosomal membrane fractions (LP1). Hippocampal slices were preincubated with anisomycin $(40 \mu \mathrm{M}, 15 \mathrm{~min})$ and processed 30 min after DHPG treatment to LP1 fractions. STEP protein expression increased significantly in the absence of anisomycin (Fig. 3A). DHPG treatment significantly decreased levels of GluR1 and GluR2, consistent with previous findings (Snyder et al., 2001). Anisomycin blocked both STEP translation and the endocytosis of GluR1 and GluR2. These results indicate that increased STEP synthesis is correlated with increased AMPAR internalization. 


\section{STEP induces AMPAR endocytosis}

If STEP is involved in endocytosis of GluR1/GluR2-containing AMPARs, we reasoned that the addition of wild-type STEP (TAT-STEP WT), even in the absence of DHPG stimulation, might increase AMPAR internalization. The addition of TAT-STEP WT ( $2 \mu \mathrm{M}, 30 \mathrm{~min})$ to hippocampal slices decreased expression of both GluR1 and GluR2 in the synaptic membrane fraction LP1 $(47 \pm 10 \%$ and $58 \pm 8 \%$ compared with the TAT-Myc treated control; $p<0.01$ ) (Fig. $3 B$ ). In contrast, the expression of $\mathrm{GABA}_{\mathrm{A}} \beta 2 / 3$ in the LP1 fraction was not changed.

\section{TAT-STEP [C/S] blocks DHPG-induced} AMPA receptor endocytosis

To test the specificity of the effects of STEP on GluR1- and GluR2-containing AMPARs, we next treated hippocampal slices with TAT-STEP $[\mathrm{C} / \mathrm{S}]$. This construct contains a point mutation in the catalytic domain that renders it inactive. It functions as a substrate-trapping protein that binds to substrates but does not release them, because release requires dephosphorylation (Snyder et al., 2005; Paul et al., 2007). Hippocampal slices were preincubated with TAT-Myc or TAT-STEP [C/S] ( $2 \mu \mathrm{M}$ for $30 \mathrm{~min}$ ) and then treated with or without DHPG (50 $\mu \mathrm{M}$ for $5 \mathrm{~min}$ ). Immunofluorescent staining showed nearly $100 \%$ transduction of TAT proteins into the cells after $10 \mathrm{~min}$ (data not shown), confirming previous results (Paul et al., 2007). DHPG significantly decreased both GluR1 and GluR2 expression on synaptic membranes (LP1) in the TAT-Myc control group. In contrast, TAT-STEP [C/S] blocked DHPG-induced AMPAR endocytosis (Fig. 3C). TAT-STEP [C/S] blockade of DHPG-induced internalization of GluR1 and GluR2 was further confirmed in hippocampal neuronal cultures by surface biotinylation (Fig. 3D).

Tyrosine phosphorylation of GluR2 after TAT-STEP [C/S] treatment was next examined to explore potential mechanisms. Hippocampal slice lysates were immunoprecipitated with GluR2 antibody and probed with anti-Tyr-P antibody (1:2000; MP Biomedicals). DHPG caused a decrease in the tyrosine phosphorylation of GluR2 in the TAT-Myc-treated groups. TAT-STEP [C/S] diminished the DHPG-induced decrease in tyrosine phosphorylation of GluR2 without affecting the total amount of GluR2 (Fig. 3E).

\section{DHPG-induced AMPAR endocytosis is abolished in STEP KO mice}

We next took advantage of STEP KO mice to determine whether STEP is necessary for DHPG-induced AMPAR endocytosis. We confirmed that DHPG decreased the expression of GluR1 and GluR2 in littermate WT mice in LP1 fractions obtained from hippocampal slices (GluR1, $61 \pm 6 \%$; GluR2, $67 \pm 10 \%$; $n=5$; $p<0.01$ and $p<0.05$, respectively) (Fig. 4A). Baseline synaptic expression of GluR1 and GluR2 was increased in STEP KO mice
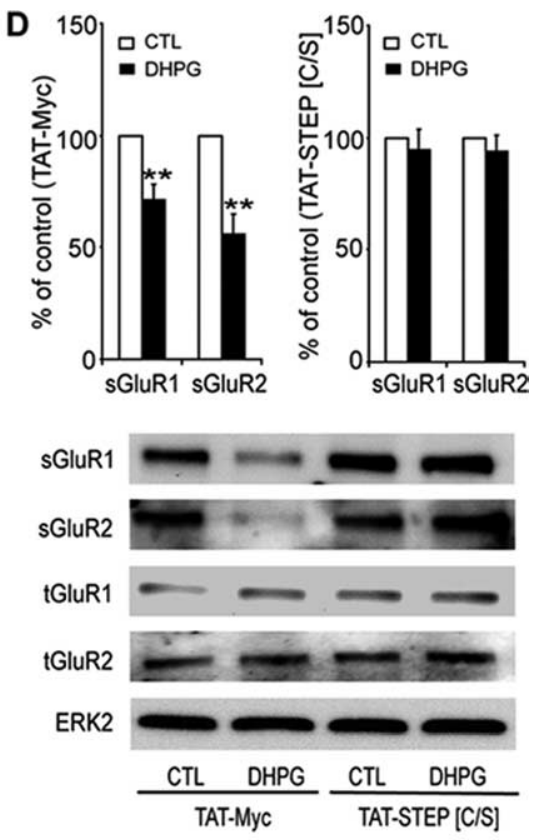

E

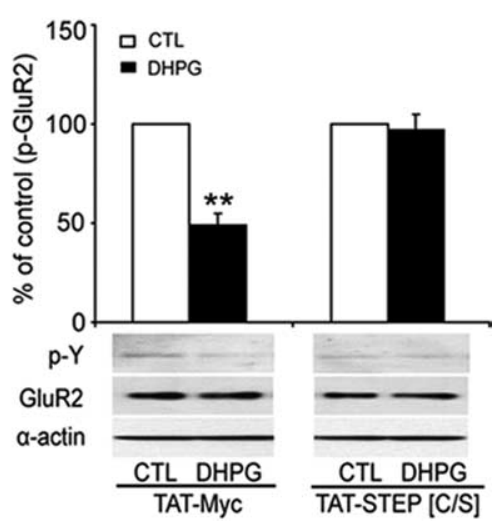

Figure 3. GluR1 and GluR2 internalization is blocked by STEP substrate-trapping construct. $A$, Expression of GluR1, GluR2, and STEP $_{61}$ in LP1 fractions from slices treated with DHPG in the absence or presence of anisomycin (Aniso). $\boldsymbol{B}$, Expression of GluR1 and GluR2 in LP1 fractions from slices treated with TAT-STEP WT fusion protein. C, Expression of GluR1 and GluR2 in LP1 fractions from expression of both GluR1 and GluR2 from biotinylated hippocampal cultures treated as in $\boldsymbol{C}$. $\boldsymbol{E}$, Tyrosine phosphorylation of GluR2 in slices treated as in C. Histograms show results after normalization to $\alpha$-actin levels. ${ }^{*} p<0.05,{ }^{* *} p<0.01 ; n=4-5$.

(GluR1, $147 \pm 12 \%$; GluR2, $135 \pm 19 \% ; n=5 ; p<0.05$ vs STEP WT CTL), indicating a constitutive inhibition of AMPARs trafficking toward the synaptic membranes by STEP. Of note, however, the DHPG-induced endocytosis of these receptors was abolished in the STEP KO mice (GluR1, $138 \pm 21 \%$; GluR2, $150 \pm$ $7 \% ; n=5)$. Together with the previous observation showing that anisomycin blocked both AMPAR endocytosis and STEP translation, our results suggest that STEP translation machinery is required for AMPA receptor redistribution.

Immunocytochemical studies confirmed that DHPG increased STEP expression in WT hippocampal cultures (Fig. 4B). We next verified that DHPG stimulation led to a decrease in GluR2 surface expression (Fig. 4C, top). However, DHPG failed to induce GluR2 endocytosis in STEP KO hippocampal cell cultures (Fig. 4C, middle). We attempted to "rescue" the original endocytosis phenotype by replacing WT TAT-STEP in KO culture; DHPG was again able to induce GluR2 internalization (Fig. $4 C$, bottom). Similar results were obtained for GluR1 in hippocampal cell cultures (data not 
A

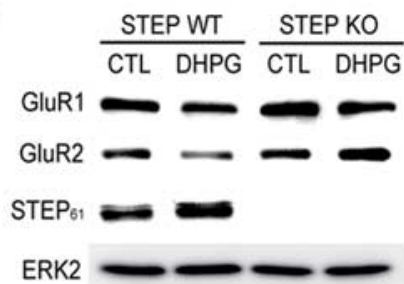

B

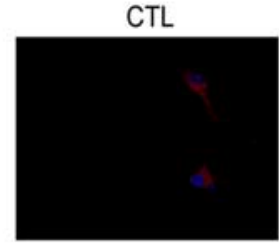

\section{$10 \mu \mathrm{M}$ DHPG}

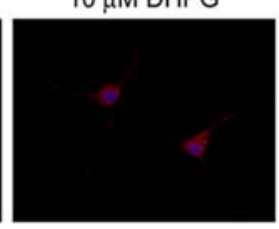

CTL

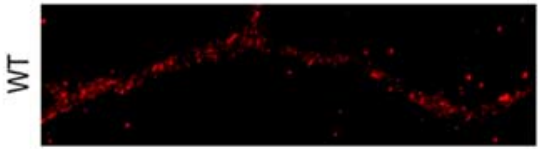

8
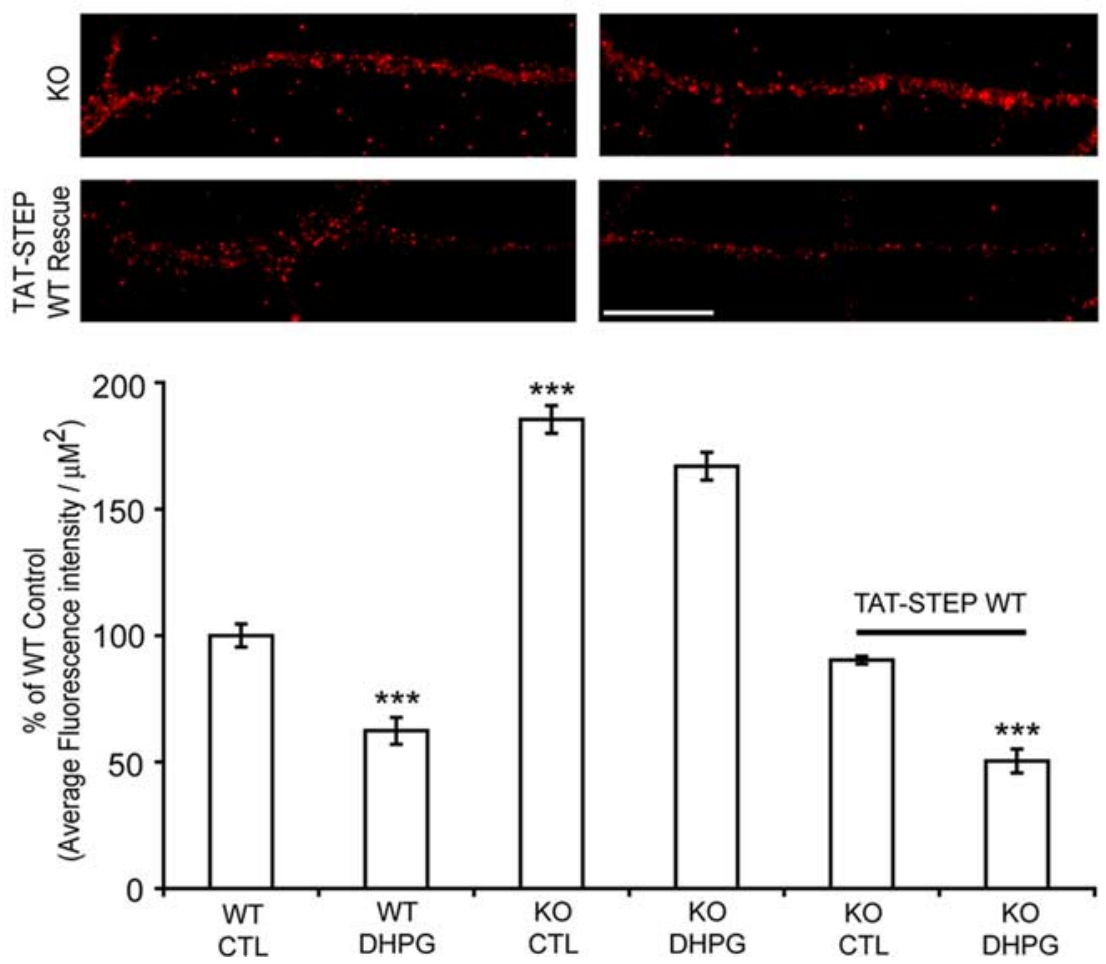

Figure 4. DHPG-induced internalization of GluR1 and GluR2 is absent in STEP KO mice. $\boldsymbol{A}$, Expression of GluR1, GluR2, and STEP $_{61}$ in LP1 fractions from slices of STEP WT littermates and STEP KO mice treated with DHPG $(n=5)$. $\boldsymbol{B}$, Fluorescence staining of STEP in hippocampal neuronal cultures treated with DHPG. Scale bar, $100 \mu \mathrm{m}$. C, Surface labeling of GluR2 in STEPWT (top) and STEP KO (middle) hippocampal neuronal cultures treated without or with DHPG. Bottom, Normalization of GluR2 surface expression in STEP KO cultures preincubated with TAT-STEP WT followed by DHPG treatment $(n=3)$ ). Scale bar, $20 \mu \mathrm{m}$. ${ }^{*} p<0.05$, ${ }^{* *} p<0.01,{ }^{* * *} p<0.001$ versus WT CTL.

shown). These results suggest that STEP is required for the DHPGinduced AMPAR endocytosis.

\section{Discussion}

The primary findings show that STEP is required for DHPG-induced AMPAR redistribution. TAT-STEP WT causes AMPAR internalization, and substrate-trapping TAT-STEP [C/S] blocks DHPG-induced AMPAR internalization. Furthermore, DHPG-induced AMPAR internalization is absent in STEP KOs but can be recovered by replacing STEP.

\section{DHPG-induced translation of STEP}

We have demonstrated that mGluR activation increases STEP expression within minutes of DHPG application to hippocampal slices and primary cultures. STEP expression was blocked by translational inhibitors anisomycin and cycloheximide, but not by the transcriptional inhibitor actinomycin D. Biochemical and electrophysiology findings demonstrate a requirement for new protein synthesis during DHPG-dependent LTD under some (Huber et al., 2000; Banko et al., 2006) but not all (Moult et al., 2008) conditions. The identities of rapidly translated protein(s) are, however, unknown.

Our findings identify STEP as a candidate protein. Activity-dependent STEP translation and DHPG-LTD requires the activation of ERK and PI3K pathways (Gallagher et al., 2004; Hou and Klann, 2004; Hu et al., 2007; Ronesi and Huber, 2008). We show here that STEP is rapidly synthesized in the synaptosomal fraction after DHPG stimulation and is dependent on activation of both MAPK and PI3K pathways. This observation fits with a growing number of studies suggesting the convergence of both pathways in the regulation of local protein synthesis in dendrites (Wang and Tiedge, 2004). In addition, preliminary data indicates that STEP is rapidly degraded after synaptic stimulation, and we speculate that the de novo translation of STEP after DHPG stimulation may be a mechanism to replenish STEP.

\section{STEP is involved in}

\section{AMPAR internalization}

AMPAR trafficking has been implicated in synaptic plasticity (Collingridge et al., 2004). AMPAR insertion into synaptic membranes leads to the expression and maintenance of LTP, whereas AMPAR removal may mediate some forms of LTD. The present findings suggest that STEP is involved in the removal of AMPARs from synaptic membranes after DHPG stimulation. We show that AMPAR endocytosis requires STEP in synaptic membraneenriched fractions. Furthermore, WT STEP increased, whereas a substratetrapping protein blocked, DHPG-induced internalization of both GluR1- and GluR2-subunit-containing AMPARs. Inactive TAT-STEP $[\mathrm{C} / \mathrm{S}]$ binds to its substrates and prevents their tyrosine dephosphorylation (Paul et al., 2003, 2007; Snyder et al., 2005). Adding this construct to hippocampal slices blocked the DHPG-induced tyrosine dephosphorylation of GluR2. This is consistent with an earlier study showing that GluR2, but not GluR1, was tyrosine dephosphorylated in DHPG-LTD, implicating the involvement of an unknown PTP in this process (Moult et al., 2006). We now suggest that this PTP is STEP.

If STEP mediates DHPG-induced AMPAR endocytosis, this 
process should be absent in STEP KO mice, assuming that no compensation occurred. Consistent with this hypothesis, we show a significant decrease in DHPG-induced internalization of GluR1 and GluR2 by immunoblot analyses of hippocampal slices and by immunocytochemical staining of hippocampal cultures. Most important, we were able to "rescue" the phenotype by restoring STEP protein to the KO cultures, suggesting that the deficit had been caused by the loss of STEP function.

Of particular relevance to the present findings, a previous study showed that the addition of $\beta$-amyloid to cortical cultures activates STEP. Active STEP in turn dephosphorylates the regulatory $\mathrm{Tyr}^{1472}$ on the NR2B subunit to promote NMDAR internalization (Snyder et al., 2005). Together, these findings implicate STEP in the internalization of both glutamate receptor subfamilies after specific types of synaptic stimulations.

\section{The role of STEP in AMPAR internalization}

STEP regulates synaptic function through tyrosine dephosphorylation of several synaptic proteins. It dephosphorylates and inactivates the MAPK proteins ERK1/2 and p38, and the tyrosine kinase Fyn (Nguyen et al., 2002; Muñoz et al., 2003; Paul et al., 2003). In addition, STEP dephosphorylates the regulatory NR2B$\mathrm{Tyr}^{1472}$ residue of NMDARs, which leads to the internalization of the NMDAR complex (Snyder et al., 2005). Here we show that STEP regulates GluR2 dephosphorylation after mGluR activation. This dephosphorylation is probably required for AMPAR internalization. Because ERK1/2 is required for STEP translation, the dephosphorylation of ERK1/2 could be part of a feedback mechanism that regulates STEP level after mGluR activation. In addition, p38 MAPK has been implicated in mGluR-LTD (Rush et al., 2002; Huang et al., 2004; Moult et al., 2008), specifically in a translation-independent form (Moult et al., 2008). It is possible that STEP could also provide a feedback inhibition of p38 during this form of LTD, a hypothesis that we are currently testing.

\section{References}

Banko JL, Hou L, Poulin F, Sonenberg N, Klann E (2006) Regulation of eukaryotic initiation factor $4 \mathrm{E}$ by converging signaling pathways during metabotropic glutamate receptor-dependent long-term depression. J Neurosci 26:2167-2173.

Boulanger LM, Lombroso PJ, Raghunathan A, During MJ, Wahle P, Naegele JR (1995) Cellular and molecular characterization of a brain-enriched protein tyrosine phosphatase. J Neurosci 15:1532-1544.

Braithwaite SP, Adkisson M, Leung J, Nava A, Masterson B, Urfer R, Oksenberg D, Nikolich K (2006a) Regulation of NMDA receptor trafficking and function by striatal-enriched tyrosine phosphatase (STEP). Eur J Neurosci 23:2847-2856.

Braithwaite SP, Paul S, Nairn AC, Lombroso PJ (2006b) Synaptic plasticity: one STEP at a time. Trends Neurosci 29:452-458.

Collingridge GL, Isaac JT, Wang YT (2004) Receptor trafficking and synaptic plasticity. Nat Rev Neurosci 5:952-962.

Dunah AW, Standaert DG (2001) Dopamine $\mathrm{D}_{1}$ receptor-dependent trafficking of striatal NMDA glutamate receptors to the postsynaptic membrane. J Neurosci 21:5546-5558.

Gallagher SM, Daly CA, Bear MF, Huber KM (2004) Extracellular signalregulated protein kinase activation is required for metabotropic glutamate receptor-dependent long-term depression in hippocampal area CA1. J Neurosci 24:4859-4864.

Hou L, Klann E (2004) Activation of the phosphoinositide 3-kinase-Aktmammalian target of rapamycin signaling pathway is required for metabotropic glutamate receptor-dependent long-term depression. J Neurosci 24:6352-6361.

Hu Y, Zhang Y, Venkitaramani DV, Lombroso PJ (2007) Translation of striatal-enriched protein tyrosine phosphatase (STEP) after beta1adrenergic receptor stimulation. J Neurochem 103:531-541.

Huang CC, Hsu KS (2006) Sustained activation of metabotropic glutamate receptor 5 and protein tyrosine phosphatase mediate the expression of
(S)-3,5-dihydroxyphenylglycine-induced long-term depression in the hippocampal CA1 region. J Neurochem 96:179-194.

Huang CC, You JL, Wu MY, Hsu KS (2004) Rap1-induced p38 mitogenactivated protein kinase activation facilitates AMPA receptor trafficking via the GDI.Rab5 complex. Potential role in (S)-3,5-dihydroxyphenylglycineinduced long term depression. J Biol Chem 279:12286-12292.

Huber KM, Kayser MS, Bear MF (2000) Role for rapid dendritic protein synthesis in hippocampal mGluR-dependent long-term depression. Science 288:1254-1257.

Huber KM, Roder JC, Bear MF (2001) Chemical induction of mGluR5- and protein synthesis-dependent long-term depression in hippocampal area CA1. J Neurophysiol 86:321-325.

Moult PR, Gladding CM, Sanderson TM, Fitzjohn SM, Bashir ZI, Molnar E, Collingridge GL (2006) Tyrosine phosphatases regulate AMPA receptor trafficking during metabotropic glutamate receptor-mediated long-term depression. J Neurosci 26:2544-2554.

Moult PR, Corrêa SA, Collingridge GL, Fitzjohn SM, Bashir ZI (2008) Coactivation of $\mathrm{p} 38$ mitogen-activated protein kinase and protein tyrosine phosphatase underlies metabotropic glutamate receptor-dependent long-term depression. J Physiol 586:2499-2510.

MuñozJJ, Tárrega C, Blanco-Aparicio C, Pulido R (2003) Differential interaction of the tyrosine phosphatases PTP-SL, STEP and HePTP with the mitogen-activated protein kinases ERK1/2 and p38alpha is determined by a kinase specificity sequence and influenced by reducing agents. Biochem J 372:193-201.

Nguyen TH, Liu J, Lombroso PJ (2002) Striatal enriched phosphatase 61 dephosphorylates Fyn at phosphotyrosine 420. J Biol Chem 277:24274-24279.

Oyama T, Goto S, Nishi T, Sato K, Yamada K, Yoshikawa M, Ushio Y (1995) Immunocytochemical localization of the striatal enriched protein tyrosine phosphatase in the rat striatum: a light and electron microscopic study with a complementary DNA-generated polyclonal antibody. Neuroscience 69:869-880.

Palmer MJ, Irving AJ, Seabrook GR, Jane DE, Collingridge GL (1997) The group I mGlu receptor agonist DHPG induces a novel form of LTD in the CA1 region of the hippocampus. Neuropharmacology 36:1517-1532.

Paul S, Nairn AC, Wang P, Lombroso PJ (2003) NMDA-mediated activation of the tyrosine phosphatase STEP regulates the duration of ERK signaling. Nat Neurosci 6:34-42.

Paul S, Olausson P, Venkitaramani DV, Ruchkina I, Moran TD, Tronson N, Mills E, Hakim S, Salter MW, Taylor JR, Lombroso PJ (2007) The striatalenriched protein tyrosine phosphatase gates long-term potentiation and fear memory in the lateral amygdala. Biol Psychiatry 61:1049-1061.

Pelkey KA, Askalan R, Paul S, Kalia LV, Nguyen TH, Pitcher GM, Salter MW, Lombroso PJ (2002) Tyrosine phosphatase STEP is a tonic brake on induction of long-term potentiation. Neuron 34:127-138.

Ronesi JA, Huber KM (2008) Homer interactions are necessary for metabotropic glutamate receptor-induced long-term depression and translational activation. J Neurosci 28:543-547.

Rush AM, Wu J, Rowan MJ, Anwyl R (2002) Group I metabotropic glutamate receptor (mGluR)-dependent long-term depression mediated via p38 mitogen-activated protein kinase is inhibited by previous highfrequency stimulation and activation of mGluRs and protein kinase $\mathrm{C}$ in the rat dentate gyrus in vitro. J Neurosci 22:6121-6128.

Scheetz AJ, Nairn AC, Constantine-Paton M (2000) NMDA receptor-mediated control of protein synthesis at developing synapses. Nat Neurosci 3:211-216.

Snyder EM, Philpot BD, Huber KM, Dong X, Fallon JR, Bear MF (2001) Internalization of ionotropic glutamate receptors in response to mGluR activation. Nat Neurosci 4:1079-1085.

Snyder EM, Nong Y, Almeida CG, Paul S, Moran T, Choi EY, Nairn AC, Salter MW, Lombroso PJ, Gouras GK, Greengard P (2005) Regulation of NMDA receptor trafficking by amyloid-beta. Nat Neurosci 8:1051-1058.

Tai CY, Mysore SP, Chiu C, Schuman EM (2007) Activity-regulated $\mathrm{N}$-cadherin endocytosis. Neuron 54:771-785.

Venkitaramani DV, Paul S, Zhang Y, Kurup P, Ding L, Tressler L, Allen M, Sacca R, Picciotto MR, Lombroso PJ (2008) Knockout of striatal enriched protein tyrosine phosphatase in mice results in increased ERK1/2 phosphorylation. Synapse, in press.

Volk LJ, Daly CA, Huber KM (2006) Differential roles for group $1 \mathrm{mGluR}$ subtypes in induction and expression of chemically induced hippocampal long-term depression. J Neurophysiol 95:2427-2438.

Wang H, Tiedge H (2004) Translational control at the synapse. Neuroscientist 10:456-466. 